\title{
River organic matter shapes microbial communities in the sediment of the Rhône prodelta
}

\author{
Sonja K Fagervold ${ }^{1,2}$, Solveig Bourgeois ${ }^{1,2}$, Audrey M Pruski ${ }^{1,2}$, François Charles ${ }^{1,2}$, \\ Philippe Kerhervé ${ }^{3,4}$, Gilles Vétion ${ }^{1,2}$ and Pierre E Galand ${ }^{1,2}$ \\ ${ }^{1}$ Sorbonne Universités, UPMC Univ Paris 06, UMR 8222, LECOB, Observatoire Océanologique, Banyuls-sur-Mer, \\ France; ${ }^{2}$ CNRS, UMR 8222, LECOB, Observatoire Océanologique, Banyuls-sur-Mer, France; ${ }^{3}$ CNRS, Centre de \\ Formation et de Recherche sur les Environnements Méditerranéens, UMR 5110, Perpignan, France and \\ ${ }^{4}$ Univ. Perpignan Via Domitia, Centre de Formation et de Recherche sur les Environnements Méditerranéens, \\ UMR 5110, Perpignan, France
}

\begin{abstract}
Microbial-driven organic matter (OM) degradation is a cornerstone of benthic community functioning, but little is known about the relation between $\mathrm{OM}$ and community composition. Here we use Rhône prodelta sediments to test the hypothesis that OM quality and source are fundamental structuring factors for bacterial communities in benthic environments. Sampling was performed on four occasions corresponding to contrasting river-flow regimes, and bacterial communities from seven different depths were analyzed by pyrosequencing of 16S rRNA gene amplicons. The sediment matrix was characterized using over 20 environmental variables including bulk parameters (for example, total nitrogen, carbon, OM, porosity and particle size), as well as parameters describing the OM quality and source (for example, pigments, total lipids and amino acids and $\delta^{13} \mathrm{C}$ ), and molecular-level biomarkers like fatty acids. Our results show that the variance of the microbial community was best explained by $\delta^{13} \mathrm{C}$ values, indicative of the OM source, and the proportion of saturated or polyunsaturated fatty acids, describing OM lability. These parameters were traced back to seasonal differences in the river flow, delivering $\mathrm{OM}$ of different quality and origin, and were directly associated with several frequent bacterial operational taxonomic units. However, the contextual parameters, which explained at most $17 \%$ of the variance, were not always the key for understanding the community assembly. Co-occurrence and phylogenetic diversity analysis indicated that bacteria-bacteria interactions were also significant. In conclusion, the drivers structuring the microbial community changed with time but remain closely linked with the river OM input.

The ISME Journal (2014) 8, 2327-2338; doi:10.1038/ismej.2014.86; published online 23 May 2014

Subject Category: Microbial population and community ecology

Keywords: organic matter quality; microbial community structure; sediments; prodelta
\end{abstract}

\section{Introduction}

Organic carbon is one of the most fundamental factors shaping marine sediment microbial communities (Jorgensen et al., 2012). However, sediment organic matter (OM) is a complex and heterogeneous mixture of high- and low-molecular-weight organic carbon compounds derived from multiple sources (for example, marine or terrestrial) at different states of degradation. Generally, land-derived $\mathrm{OM}$ are thought to be more recalcitrant to degradation than plankton-derived OM (Hedges et al., 1997; Baldock et al., 2004), but in environments with a mixture of both kinds, different microbial groups can allow refractory OM to be metabolized through mutualistic relationships (Bianchi, 2011). Such relationships

Correspondence: S Fagervold, Observatoire Océanologique, Ave du Fontaulé, CNRS/UPMC, Banyuls-sur-Mer 66650, France. E-mail: fagervold@obs-banyuls.fr

Received 28 January 2014; revised 15 April 2014; accepted 17 April 2014; published online 23 May 2014 are, however, poorly understood as microbial communities are rarely investigated in the same context as $\mathrm{OM}$ source or $\mathrm{OM}$ quality, defined here as composition and lability.

The structure or function of sediment microbial communities has been linked with pigment concentrations, used as indicators of OM freshness (Polymenakou et al., 2005; Franco et al., 2007; Bienhold et al., 2012), but other classes of compounds, which might give relevant insight both into the lability and origin of the organic component, are often not considered. For instance, the state of degradation of the $\mathrm{OM}$ can be estimated from its amino acid composition using the degradation index) (Dauwe and Middelburg, 1998), whereas the carbon isotopic signature $\left(\delta^{13} \mathrm{C}\right)$ can be used to assess OM origin (Hedges et al., 1997). Furthermore, molecular-level proxies such as fatty acid profiling or the proportion of labile polyunsaturated fatty acids (PUFA) enables the distinction of OM sources (that is, terrestrial plants, phytoplankton or zooplankton) and provides insight into the degree of 
alteration of these sources (Bianchi and Canuel, 2011). Such proxies could thus be very useful for a holistic characterization of OM quality.

The OM of both terrestrial and marine origin is efficiently remineralized in muddy deltaic environments (Aller, 1998) that are characterized by episodic mixing events and recurring redox successions, allowing for the coexistence of microbial consortia with different biogeochemical functions (Aller et al., 2010). The rapid and mostly anaerobic OM cycling coupled to sulfur, iron and manganese cycling makes this environment truly unique and highly diverse in terms of microbial-driven processes (Froelich et al., 1979; Madrid et al., 2001; Aller and Aller, 2004; Madrid et al., 2006; Aller et al., 2010). Major microbial players in deltaic environment are known chemoorganotrophic bacteria belonging to the phyla Bacteroidetes, Actinobacteria and Planctomycetes as well as sulfateoxidizing bacteria, sulfate reducers and nitrifiers (Madrid et al., 2001; Aller and Aller, 2004; Madrid et al., 2006). The microbial community from sediments of the Rhône River prodelta (NW Mediterranean Sea) has never been described, but the high deposition and sedimentation rates (Radakovitch et al., 1999; Miralles et al., 2006), high oxygen consumption and high remineralization rates (Lansard et al., 2008; Cathalot et al., 2010; Pastor et al., 2011) suggest the presence of communities similar to the ones found in other dynamic deltaic environments.

The Rhône River accounts for $80 \%$ of the riverine particle inputs into the Gulf of Lions (Aloisi et al., 1979), most of it being delivered during episodic and extreme flood events (Pont, 1997; Antonelli et al., 2008). The highly dynamic prodelta of the Rhône River, with OM from contrasting origins (marine vs terrestrial) including modern vascular C3 plant detritus, soils and freshwater phytoplankton (Kim et al., 2010; Bourgeois et al., 2011; Cathalot et al., 2013) can thus be used as a model system to test the hypothesis that the OM quality and source are fundamental structuring factors for the microbial communities in benthic environments. To obtain samples reflecting the variability of sources, sediments from the prodelta were seasonally sampled at seven different layers for a coupled study of both $\mathrm{OM}$ and microbial communities. The microbial communities were analyzed by pyrosequencing and the sediment $\mathrm{OM}$ characterized by using molecular-level proxies and bulk analyses for a complete description of OM quality and source.

\section{Materials and methods}

Study site and sampling procedures

With a mean annual discharge of $1700 \mathrm{~m}^{3} \mathrm{~s}^{-1}$ (Pont, 1997; Sempéré et al., 2000), the Rhône River represents an important input of freshwater and organic carbon to the Mediterranean Sea. Material deposited in the immediate vicinity of the river mouth forms a muddy sand bar, and as a result of sediment remobilization and displacement by waves and currents (Marion et al., 2010), the fine-grain prodelta sediments cover an area of $50 \mathrm{~km}^{2}$ (Lansard et al., 2009) of the inner shelf. Sediments were collected at station 'Mesurho' $2.5 \mathrm{~km}$ off the river mouth, near the sea buoy marked 'Roustan-Est' $\left(43^{\circ} 19^{\prime} 6.966^{\prime} \mathrm{N}, 4^{\circ} 51^{\prime} 58.2^{\prime}\right)$, at $\sim 20 \mathrm{~m}$ water depth on four different occasions during 2010 (Supplementary Figure S1). This well-described station (Marion et al., 2010; Charles et al., 2014) was chosen because it is under the influence of the river discharge, but not inside the main flow channel of the Rhône, and because the sediments underneath the buoy are spared from trawling activity. On the first sampling date, 19 February, the sampling was performed at the beginning of a flood event $\left(3110 \mathrm{~m}^{3} \mathrm{~s}^{-1}\right)$, on 16 April the sampling was done at the end of a river flow peak $\left(1450 \mathrm{~m}^{3} \mathrm{~s}^{-1}\right)$, on 30 June the station was sampled after an episode of river discharge peaking below the mean flood threshold $\left(3000 \mathrm{~m}^{3-1} \mathrm{~s}^{-1}\right)$, and on 27 August, the sampling was completed after a period of low river discharge (Supplementary Figure S1B). Sediment cores (9.5 cm diameter, $60 \mathrm{~cm}$ height) were collected with a multicorer MUC 8/100 (Oktopus $\mathrm{GmbH}$, Kiel, Germany). At each sampling date, three undisturbed cores were processed on board. Cores were sliced in seven horizontal layers $(0-0.5,0.5-1$, $1-2,2-3,3-5,5-7$ and $7-10 \mathrm{~cm})$. Each layer was homogenized and separated in three aliquots that were stored at $-20^{\circ} \mathrm{C}$. One aliquot was used for pigment and grain-size measurements, another for bulk and biochemical analyses and the last for bacterial community analyses. Except for pigment and sediment grain size, all sediment subsamples were freeze-dried before analyses.

\section{Determination of sediment characteristics (contextual parameters)}

Sediment granulometry was measured using a Malvern Mastersizer 2000 laser microgranulometer (Malvern, Worcestershire, UK). Grain size is expressed as $d(0.5)$ corresponding to the median of the size distribution based on the equivalent spherical volume diameters. The proportion of different particle sizes was used to describe the texture of sediment (Table 1). Total OM content was calculated by measuring the weight loss of freezedried sediment after combustion $\left(450^{\circ} \mathrm{C}, 5 \mathrm{~h}\right)$. Total nitrogen and total organic carbon concentrations were determined using an automatic CN-analyzer (LECO 2000, LECO, St-Joseph, MI, USA) after acidification with $2 \mathrm{M} \mathrm{HCl}$ (overnight, at $50^{\circ} \mathrm{C}$ ) to remove carbonates before the analyses of organic carbon (Cauwet et al., 1990). Stable carbon isotopes were measured on acidified samples according to the protocol described in Kerhervé et al. (2001) and analyzed on an elemental analyzer (EA 3000 
Table 1 Overview of the contextual parameters that were measured and compared with the microbial community

\begin{tabular}{|c|c|}
\hline Abbreviation & Description \\
\hline \multicolumn{2}{|c|}{ Bulk parameters } \\
\hline TOC $^{\mathrm{a}}$ & Total organic carbon \\
\hline $\mathrm{TN}^{\mathrm{a}}$ & Total nitrogen \\
\hline $\mathrm{OM}^{\mathrm{a}}$ & Total organic matter \\
\hline \multicolumn{2}{|c|}{ Hydrodynamic forces related } \\
\hline Clay_prop & Proportion of particles $<4 \mu \mathrm{m}$ \\
\hline Silt_prop & Proportion of particles between 4 and $63 \mu \mathrm{m}$ \\
\hline Sand_prop & Proportion of particles between 63 and $2000 \mu \mathrm{m}$ \\
\hline Porosity & Porosity \\
\hline d_0.5 & Median particle diameter \\
\hline \multicolumn{2}{|c|}{ Lability and composition } \\
\hline Chla ${ }^{\mathrm{b}}$ & Chlorophyll $a$ concentration \\
\hline Chlb $^{\mathrm{b}}$ & Chlorophyll $b$ concentration \\
\hline Phaeo $^{\mathrm{b}}$ & Phaeophytin concentration \\
\hline THAA $^{\mathrm{a}}$ & Total hydrolysable amino acids \\
\hline $\mathrm{FA}^{\mathrm{b}}$ & Total fatty acids \\
\hline Chlb/Chla & Chlorophyll $b / a$ proportion \\
\hline $\mathrm{C} / \mathrm{N}$ & Carbon to nitrogen ratio \\
\hline \multicolumn{2}{|l|}{ Ratio parameter } \\
\hline THAA_yield & THAA proportion to total carbon \\
\hline FA_yield & Total FA proportion to total carbon \\
\hline PUFA & Polyunsaturated FA proportion of total FAs \\
\hline MUFA & Monounsaturated FA proportion of total FAs \\
\hline SAFA & Saturated FA proportion of total FAs \\
\hline BACT_prop & Proportion of bacterial-derived FA of total FAs \\
\hline \multicolumn{2}{|c|}{ Source related } \\
\hline Phyto_PUFA ${ }^{\mathrm{c}}$ & The proportion of phytoplankton PUFA of total FAs \\
\hline TERR_FA ${ }^{\mathrm{d}}$ & The proportion of terrestrial-derived FA of total FAs \\
\hline$\delta^{13} \mathrm{C}^{-}$ & Delta C13 values $(\%)$ \\
\hline \multicolumn{2}{|l|}{ Indices } \\
\hline PI & Pigment index $($ Chla $\times 100 /($ Chla + Phaeo $))$ \\
\hline DI & Degradation index based upon THAA \\
\hline
\end{tabular}

${ }^{a}$ Unit used was $\mathrm{mgg}^{-1}$ dry weight (DW) sediment.

bUnit used was $\mu \mathrm{gg}^{-1} \mathrm{DW}$ sediment.

'PHYTO_PUFA includes the following FAs: C16:2w4, C16:3w4,

C18:3w6, C18:4w3, C20:2w6, C20:3w6, C20:4w6, C20:4w3, C20:5w3 and C22:6w3.

dTERR FA includes the following FAs: C26:0, C28:0, C30:0, C18:2w6 and C18:3w3.

Eurovector, Eurovector, Milan, Italy) coupled with an isotopic ratio/mass spectrometer (GVI Isoprime, GVi, Cheadle, UK). Pigments were extracted as described in Bourgeois et al. (2011). The fluorescence of the extracts was measured according to the method developed by Neveux and Lantoine (1993). Amino acids were released by acid hydrolysis (HCl $6 \mathrm{~N}, 100{ }^{\circ} \mathrm{C}$ for $24 \mathrm{~h}$ ) and the hydrolysates were treated as described in Bourgeois et al. (2011). Hydrolysable amino acids were analyzed by reversed-phase high-performance liquid chromatography as isoindole derivatives following precolumn derivatization with orthophtaldialdehyde (Lindroth and Mopper, 1979). Fatty acids were analyzed as methyl esters as previously described (Bourgeois et al., 2011) using a Saturn 2100T iontrap GC-MS instrument (VARIAN, Les Ulis, France) equipped with a fused-silica-capillary column (Factor Four, VF-Waxms, $30 \mathrm{~m} \times 0.25 \mathrm{~mm}$ ID, $0.25 \mu \mathrm{m}$ film thickness, VARIAN). Porosity was calculated from natural moisture content assuming a density of $2.63 \mathrm{~g} \mathrm{~cm}^{-3}$ for dry sediment and corrected for seawater salinity.

\section{DNA extraction and pyrosequencing}

DNA was extracted using the UltraClean Soil DNA Isolation Kit (MoBio, Carlsbad, CA, USA) from $\sim 100 \mathrm{mg}$ of freeze-dried sediment according to the manufacturer's protocol with some modifications. Namely, three bead beatings of $45 \mathrm{~s}$ at $30 \mathrm{rev} \min ^{-1}$ were followed by 3 thermal shocks ( $15 \mathrm{~s}$ in $\mathrm{N}_{2}$ and 1 min in a water bath at $95^{\circ} \mathrm{C}$ ) to maximize cell lysis, followed by incubation for $45 \mathrm{~min}$ at $55^{\circ} \mathrm{C}$ with proteinase K. PCR amplification for pyrosequencing was performed as described in Fagervold et al. (2013) using universal bacterial primers, 27Fmod (Vergin et al., 1998), with adaptors and multiplex identifiers and a modified version of primer 519R (Teske et al., 1994). Emulsion PCR of amplicons (5 ng $\mathrm{ll}^{-1}$ from each sample) and pyrosequencing was carried out at the Genotoul platform at INRA (Toulouse, France) with Roche (Basel, Switzerland) 454 Genome Sequencer FLX and Titanium chemistry.

\section{Sequence analysis}

Sequence analysis was performed using both QIIME (Caporaso et al., 2010, v. 1.4.0-1.7.0) and Mothur (Schloss et al., 2009, v. 1.23-1.28). Sequences were denoised using Ampliconnoise and chimera checked using Perseus (Quince et al., 2011). This output was clustered using Uclust (Edgar, 2010) at $97 \%$ sequence identity level that resulted in 13426 operational taxonomic units (OTUs). A representative sequence from each OTU was classified using the Ribosomal Database Project (RDP) classifier (Wang et al., 2007) and a training set extracted from the Silva108 database (Quast et al., 2013). These same sequences were aligned in Mothur and filtered (minimum length $200 \mathrm{bp}$ and start site 1044 in the Silva alignment). This alignment was used as a basis for $\alpha$ and $\beta$ diversity indexes where a phylogenetic tree is used as an input (UniFrac and phylocom, see below). Here, phylogenetic trees were made in QIIME using FastTree (Price et al., 2009), with the aligned sequences being additionally filtered with the lanemask. All samples were subsampled to an even depth of 450 sequences per sample to be able to compare them using $\beta$ diversity metrics. However, this resulted in two of the samples from August (sediment layers $3-5 \mathrm{~cm}$ and $5-7 \mathrm{~cm}$ ) being excluded for further analysis because they contained $<450$ sequences. When subsampling to 450 sequences per sample, we did not capture the total diversity of the samples (Supplementary Figure S2A), nevertheless, we should still be able to detect major patterns in the microbial community composition (Kuczynski et al., 2010).

To further clean the data, we excluded sequences that did not classify to the phyla level using the RDP 
classifier (probability 0.8) and were only present in one sample. This resulted in 4194 OTUs and 11276 sequences. This data set was used for further analysis and called 'OTU_total'. For comparison, we also built a data set that contained only OTUs that were present at all sampling dates (OTU_resident: 144 OTUs, 3470 sequences) and one similar to OTU_total but with all singletons and doubletons removed (OTU_trunc: $35 \%$ of the sequences; 1632 OTUs and 8714 sequences remained). All sequences have been submitted to the sequence read archive under the Bioproject accession number: PRJNA231894, ID: 231894.

\section{Statistical and taxa-environment analysis}

Rarefaction curves, evenness and diversity indexes were calculated in QIIME. To test whether samples were significantly different, pairwise comparisons were made using the weighted UniFrac metric (Lozupone and Knight, 2005; Lozupone et al., 2007) in QIIME. The significance of this comparison was determined by 1000 Monte Carlo randomizations and $P$-values are corrected for the number of comparisons (Bonferri correction).

We performed three kinds of analyses to investigate the relationships between the microbial community (using the OTU trunk table) and the contextual parameters: (1) multivariate statistics, or redundancy analysis (RDA) with forward selection, to identify the parameters that could best explain the variation in the microbial community, (2) direct Mantel tests of distance matrices based upon the bacterial community structure and the contextual parameters to test the individual parameters separately and (3) analysis using the maximal information coefficient (MIC) (Reshef et al., 2011) to identify possible associations between individual OTUs or taxa and contextual parameters. For the RDA analysis, the parameters that were tested, along with abbreviation that will be used throughout, are given in Table 1. A detailed description of the RDA analysis and the forward selection procedure is given in Supplementary Text 1. The significance of the reduced models was tested by analysis of variance with 999 permutations. Individual Mantel tests were performed with both weighted UniFrac and Bray Curtis distance matrices for the microbial community data and distance matrices (Euclidian distance) for each contextual parameter.

MIC analysis (Reshef et al., 2011) was performed using variables that had been identified as relevant by RDA and Mantel tests. MIC analysis is able to detect many kinds of correlations, not only unimodal. False discovery rates were calculated directly from an empirical null distribution with the $\mathrm{R}$ package locfdr (Efron, 2004). An association was considered significant when false discovery rate was $<1 \%$ that was equivalent to MIC $>0.48$. The matrix of MIC values $>0.48$ was used with Cytoscape 2.8.3 (Shannon et al., 2003) to visualize the network of association as described earlier (Blanquer et al., 2013). In these visualizations, bacterial OTUs and environmental parameters are represented as nodes and are connected by lines that are proportional in length to the MIC value. Finally, a SIMPER analysis was performed to investigate which OTU contributed the most to the difference in community composition between sampling times.

The different communities were also compared using indices of phylogenetic structure. The net related index (Webb et al., 2002) is based upon the mean pairwise distance (MPD) of each of the OTUs within each sample. MPD characterizes the phylogenetic distance (or the branch length) between all the OTUs in a sample. These indices were calculated by using Phylocom (Webb et al., 2008) implemented in the $\mathrm{R}$ package picante (Kembel et al., 2010). The significance was tested against a null model (999 random permutations across the entire phylogeny). To check for nonrandom co-occurrence patterns, a checkerboard score (C-score) (Stone and Roberts 1990; Horner-Devine et al., 2007) was calculated for the different OTU tables. This was tested for significance against a null model preserving sample frequencies. Statistical analysis was done using $\mathrm{R}$ (version 2.15.0, http:// www.R-project.org) and the vegan package (Oksanen et al., 2012).

\section{Results}

Prodelta sediment characteristics are variable with time

Values of the contextual parameters (see Table 1 and Supplementary Figure S3) varied with both time and depth. Most of the parameters had the highest values in April and the lowest either in June or August, with the exception of the river discharge that was highest during the February sampling (Figure 1). Total organic carbon and chlorophyll $a$ (Chla) increased from February to April, but this was not statistically significant because of a relatively large scattering of values in April (more differences with depth). Then, total organic carbon and Chla decreased in July and August (Figure 1). Variables quantifying the OM content (organic carbon, total nitrogen, Chla, chlorophyll $b$, Phaeophytin, total FA and total hydrolysable amino acid, data not shown), as well as particle size showed the same trend. The terrestrial carbon fraction, which was calculated using $\delta^{13} \mathrm{C}$ values (Vo $\beta$ and Struck, 1997), indicated that terrestrial-derived $\mathrm{OM}$ was predominant in February and April (Figure 1). Furthermore, this terrestrial OM was mostly derived from freshwater phytoplankton in April and C3 soils (soil covered by C3 plants) in June and August (Figure 2). This transition from freshwater to soil-derived OM was also supported by a fivefold decrease in the relative number of freshwater chloroplast sequences, mainly from diatoms, detected in the top layer from 
February to June (data not shown). It should also be noted that the oxygen penetration depth was 1.4-2.6 mm (C Rabouille, personal communication), meaning that most of the sediment column was anoxic at all time points.

\section{Bacterial communities change with time}

Bacterial communities were significantly clustered according to the sampling time (analysis of similarity, $R=0.6055 P=0.001$ ) but there was no significant effect of depth. Furthermore, comparisons using the weighted UniFrac metric showed that August communities were different from all others $(P<0.001)$, whereas the communities in June samples were different from April $(P=0.024)$. We also observed differences in the bacterial diversity over time and depth (Supplementary Figure S2). The richness estimates were $\sim 1000$ for all April and August samples, and changed little with depth. However, the diversity was higher in the top three layers of February samples, but decreased with depth, whereas the opposite was observed for the June samples, with the exception of the deepest layer (Supplementary Figure S2B). Evenness values showed that the February samples at 0.75 and $1.5 \mathrm{~cm}$ depths were dominated by abundant OTUs (less even), compared with the other samples.

At the phylum level, Bacteroidetes and Proteobacteria sequences dominated the microbial community but there were clear differences in their relative abundance over time (Figure 1). Bacteroidetes varied from representing $>20 \%$ of the sequences in February and April to averaging $\sim 12 \%$ in August. Deltaproteobacteria sequences were dominant in August samples (from 20\% to $30 \%$ of total sequences) and were generally less abundant in the top layer $(0-0.5 \mathrm{~cm})$. Alphaproteobacteria sequences showed opposite dynamics compared with the Deltaproteobacteria in most of the samples. They were abundant in February and April top samples $(15.4 \%$ and $24.5 \%$ in $0-0.5 \mathrm{~cm}$ layer, respectively) to then decrease, especially in August. Betaproteobacteria sequences were most abundant in June (between $17.8 \%$ and 14.8\%) and least abundant in August (between 8.9\% and 1.4\%), but the highest value was in the topmost sample in February $(18.5 \%)$.

At the OTU level, a SIMPER analysis showed that only four OTUs contributed to $>1 \%$ of the total dissimilarity when samples were grouped by month (Figure 3). The Flavobacteriaceae OTU 7940, which was the most abundant OTU of the whole study, dominated the February samples. This OTU contributed to $\sim 10 \%$ of the total sequences from the second and third layers from February but was rarely detected in the top layers. OTU11146, also a Flavobacteriaceae, was typical for the June samples and much less dominant in February samples. The Betaprotebacteria OTU 11154 was most abundant in the June samples and less abundant in the August samples. Moreover, it was relatively more abundant in the top section. OTU 11225, belonging to order Desulfuromonadales, was more abundant in August.

\section{Contextual parameters explaining variations in} microbial community structure and diversity To investigate which of the over 20 different contextual parameters could best explain the

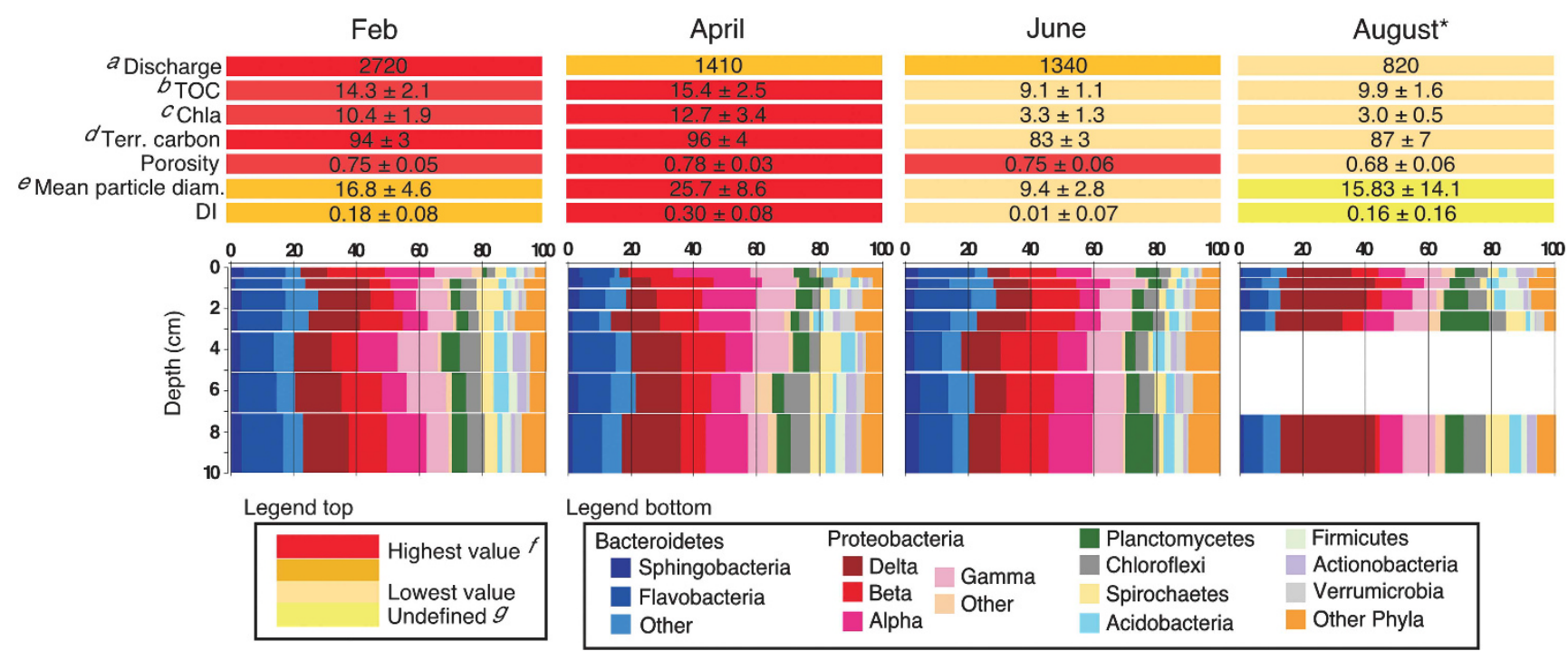

Figure 1 Top, average values $(n=7)$ and s.d. of selected contextual parameters for the Rhône prodelta sediments at different time points in 2010. Bottom, proportion of the major bacterial taxa in all samples. * Some samples are missing because they contained $<450$ sequences. ${ }^{\mathrm{a}} \mathrm{m}^{-3} \mathrm{~s}^{-1}$; ${ }^{\mathrm{b}} \mathrm{mg} \mathrm{g}{ }^{-1}$ dry weight (DW) sediment; ${ }^{\mathrm{c}} \mu \mathrm{gg}^{-1} \mathrm{DW}$ sediment; ${ }^{\mathrm{d}}$ terrestrial fraction was calculated using the $\delta^{13} \mathrm{C}$ value and a two end-members model, where terrestrial end-member was $\delta^{13} \mathrm{C}=-27.4 \pm 0.7 \%$ and marine end member is $\delta^{13} \mathrm{C}=-20.1 \pm 0.8 \%$ (Harmelin-Vivien et al., 2008; Higueras et al., 2014); ${ }^{\mathrm{e}}$ median particle diameter $(\mu \mathrm{m})$; ${ }^{\mathrm{f}}$ the coloring is different only if the values were significantly different $(P<0.05)$; ${ }^{g}$ samples where the variance was too large to determine whether differences/similarities were significant. 


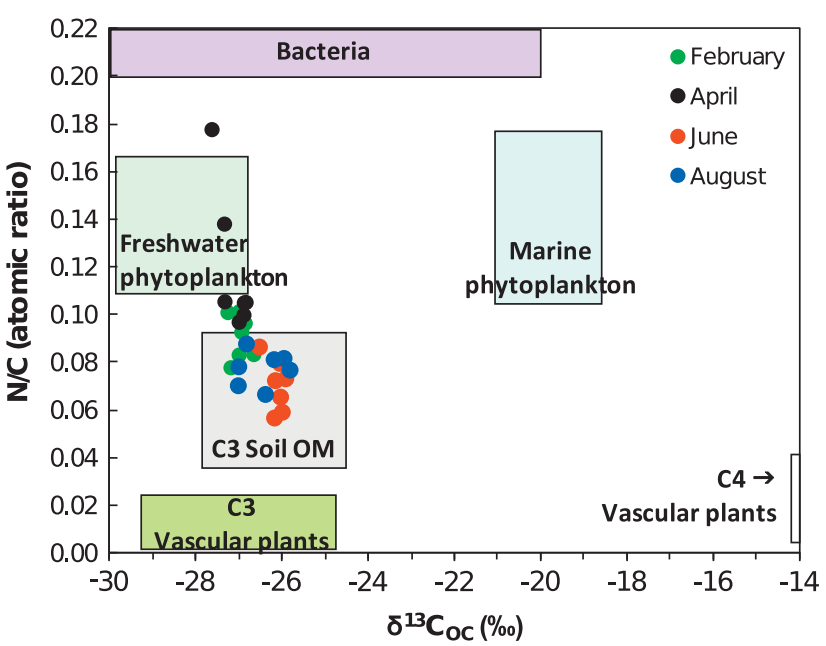

Figure 2 Plot of atomic organic nitrogen/carbon ratios (N/C (atomic ratio)) versus the stable carbon isotopic compositions $\left(\delta^{13} \mathrm{C}_{\mathrm{OC}}\right)$. Each dot represents one sample. Also plotted are the compositional ranges of potential end-member sources according to the literature (see Bourgeois et al., 2011 and references therein).

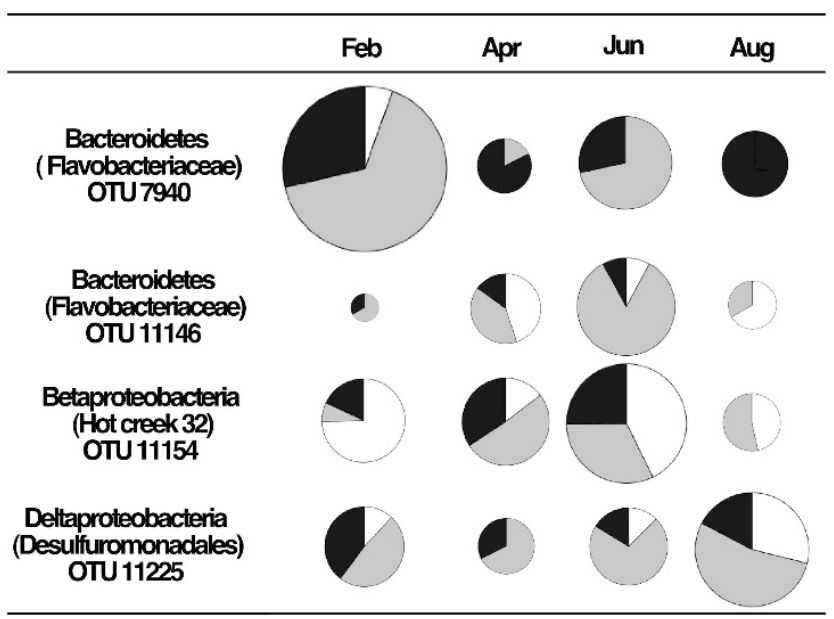

Figure 3 The four OTUs contributing the most to the difference in community composition ( $>1 \%$ ) identified by SIMPER analysis. Samples were grouped according to sampling date and the sizes of the pie charts are proportional to the number of sequences in each OTU. White denotes the top sample $(n=1)$, gray denotes the 'middle' samples, from 0.5 to $3 \mathrm{~cm}$ (average of $n=3$ ) and black denotes the 'deep' samples (average of $n=3$ ).

microbial community structure, we performed several complementary analyses. For the RDA analysis, we employed both an automatic and empirical forward selection (Supplementary Text) that resulted in the identification of seven parameters that best explained the variance of the microbial community (Figure 4). It should be noted that several of the contextual parameters co-varied. For example, Chla concentration was used as a proxy for all the quantitative OM parameters because Chla was the most significant (Supplementary Table S1 and Supplementary Text 1). Among the seven parameters, RDA analysis showed that saturated fatty acids (SAFA) could explain most of the

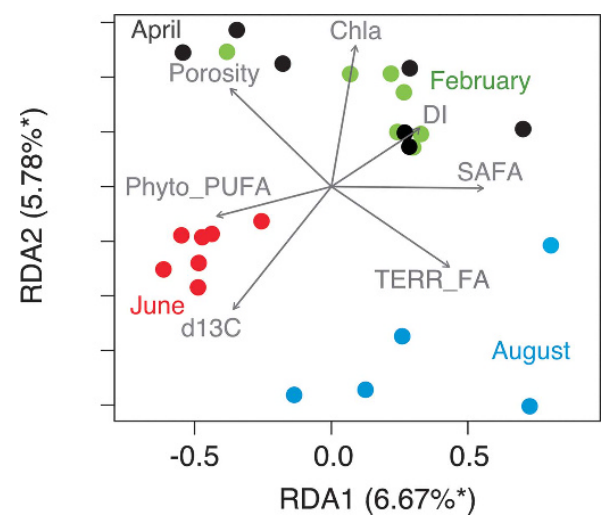

Figure 4 RDA biplot of bacterial community composition and the seven most significant contextual parameters. Each dot represents one sample. The environmental parameters shown were selected by a combined automatic and empiric forward selection (see Materials and methods). *Percentage of total variance explained by each axis. Total constrained variance is $32.63 \%$, thus RDA1 and RDA2 will represent $21.20 \%$ and $17.74 \%$, respectively, of the constrained variance.

constrained variance in the microbial population (Supplementary Table S1), and together with $\delta^{13} \mathrm{C}$ and Phyto_PUFA, these parameters explained $16.84 \%$ of the variation $(P<0.001)$. Phyto_PUFA and $\delta^{13} \mathrm{C}$ separated the June samples from the rest of the samples, whereas Chla concentration separated the February and April samples from the June and August samples, and TERR_FA and SAFA separated the August from the other sampling times (Figure 4). Direct Mantel tests showed the significance of these contextual parameters (Supplementary Figure S4), with the exception of Phyto_PUFA and degradation index.

The MIC analysis gave information on direct associations between contextual parameters and relative abundances of OTUs (Figure 5). Several OTUs had opposite associations to Phyto_PUFA and SAFA. OTU 203, an abundant OTU within the family Desulfobacteraceae, showed a positive correlation with SAFA, whereas the dominant Betaproteobacteria OTU 11154 was associated with Phyto_PUFA. The relative abundant Flavobacteriaceae OTU 7940 was positively correlated with TERR_FA. We further detected a negative correlation between $\delta^{13} \mathrm{C}$ values and Spirochaetaceae 0TU 9909 as well as Betaproteobacteria OTU 4026, suggesting that they were associated with terrestrial input. Overall, Phyto_PUFA exhibited most associations in the MIC analysis (Figure 5).

The richness of the bacterial community was significantly $(P<0.005$ for the following $)$ correlated with the carbon/nitrogen ratio $(R=0.56)$ and the proportion of clay $(R=0.54)$ only. MPD was significantly correlated to porosity $(R=0.60)$ and silt $(R=0.55)$, and negatively to SAFA $(R=-0.57)$ and TERR_FA $(R=-0.53)$. This means that when TERR_FA and SAFA were high, the OTUs were more phylogenetic clustered. 


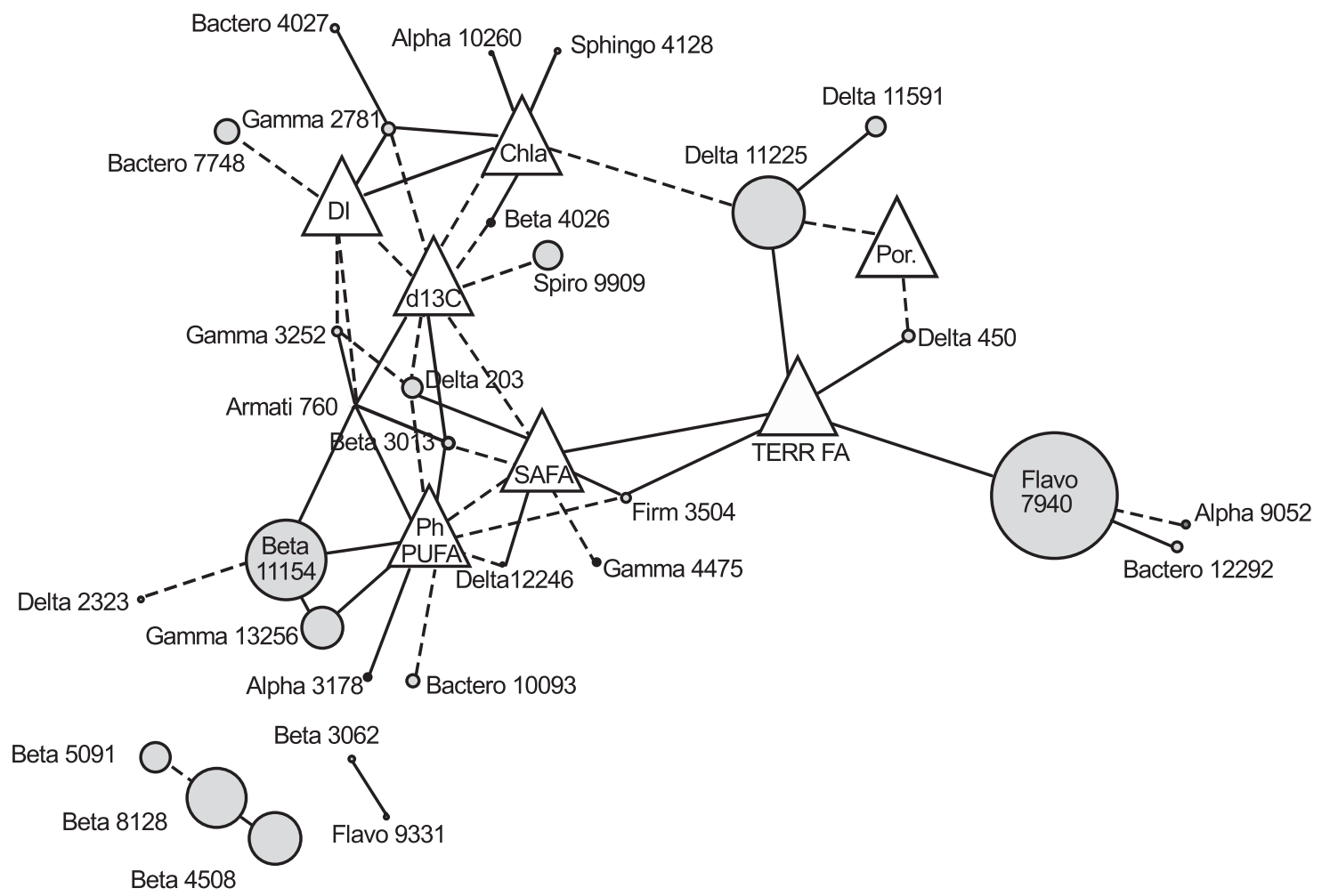

Figure 5 Associations between environmental parameters (triangles) and bacterial OTUs (circles) as identified with MIC statistics and visualized as a network. Uninterrupted lines represent positive relationships and dotted lines represent negative relationships. The sizes of the circles are proportional to the amount of sequences in the OTU.

Co-occurrence and phylogenetic clustering

To investigate whether the sediment microbial communities were structured by deterministic processes, we analyzed the co-occurrence of taxa and OTUs using the C-score (Stone and Roberts, 1990) and found that OTUs were significantly $(P<0.01)$ segregated. Furthermore, MPD values (Figure 6) showed that February and April samples were more phylogenetically dispersed (higher MPD) than June and August. In fact, there were only three samples that were significantly clustered or dispersed $(P<0.05)$; the topmost layer in February was significantly dispersed, whereas the third and fourth layers from the August core were significantly clustered.

\section{Discussion}

Bulk parameters like porosity and grain size are valuable in describing sedimentary systems and common parameters that describe labile OM, like Chla or phaeopigment concentration, have been shown to explain variance in microbial communities (Polymenakou et al., 2005; Franco et al., 2007; Bienhold et al., 2012). The variance in the microbial community in our study was, however, best explained by ratio parameters describing OM quality (SAFA and Phyto_PUFA) and source $\left(\delta^{13} \mathrm{C}\right.$ values). SAFA and Phyto_PUFA are important explanatory variables because of their different degradation potentials. SAFA are relatively resistant toward degradation. On the other hand, PUFA contain unsaturated carbon bonds that are sensitive to oxidation and are thus good proxy for very labile

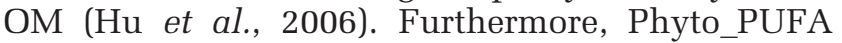
provide a useful insight onto the source of the $\mathrm{OM}$ as they are synthesized by freshwater and marine microalgae (Volkman, 2006).

The $\delta^{13} \mathrm{C}$ value, explaining significant amounts of variability in the microbial communities, is also an indicator of the source of the organic carbon. The $\delta^{13} \mathrm{C}$ values in our samples ranged from -27.67 to -25.83, indicating a predominant contribution of the Rhône River particulate OM (POM) (Darnaude et al., 2004; Higueras et al., 2014) at the expense of the marine contribution (Harmelin-Vivien et al., 2008). Higueras et al. (2014) demonstrated that depleted $\delta^{13} \mathrm{C}$ values $(<-27 \%$ ) characterized freshwater production in several Mediterranean rivers whereas enriched $\delta^{13} \mathrm{C}$ values $(>-27 \%$ ) traced predominantly the soil OM. Thus, the difference in OM quality of the prodelta sediments can be traced back to the different discharge events of the Rhône River. To summarize, the development of phytoplankton in the river accounted for increased amount, higher lability and lower degradation state of sedimentary OM in February and April. A similar seasonal trend has been shown for the same area by Harmelin-Vivien et al. (2010). Later, the flood that occurred in early June brought silty material originating from the weathering of soils. This thick 


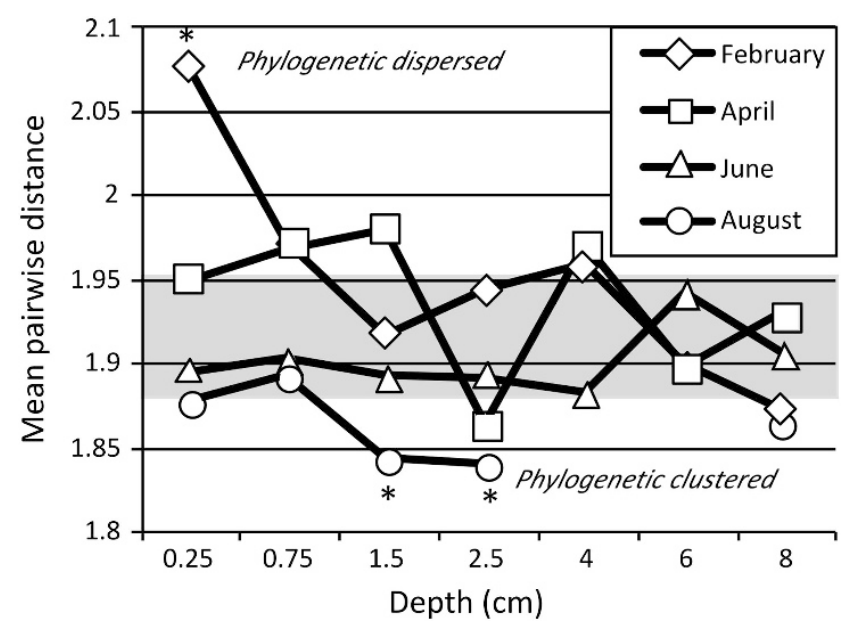

Figure 6 Phylogenetic MPD for bacterial communities from the Rhône river prodelta sediments. Gray area represents the null distributions with standard error. * Samples that are statistically significantly dispersed or clustered.

deposit was depleted in OM, more degraded and less labile than the POM delivered by the Rhône during normal discharge conditions (Bourgeois et al., 2011). Then, during the summer, the low discharge rates and the calm weather conditions were favorable to the compaction (that is, lower porosity) and further degradation of the material deposited in the prodelta. August samples were thus depleted in OM and contained relatively less terrestrial-derived OM.

Microbial community composition in the sediments also changed with sampling time. The strong temporal dynamics was reflected by the fact that none of the OTUs were present in all samples (at all times and all depths) and resident OTUs (OTUs that are present at all four sampling times) represented only $3 \%$ of the total OTUs and $30 \%$ of the sequences, similar to values reported for coastal sands (Gobet et al., 2012). Among the abundant resident OTU sequences, two flavobacterial (Bacteroidetes) OTUs (OTU 7940 and 11146) had different temporal relative abundance distribution patterns, suggesting different ecological niches. This niche differentiation was supported by the fact that unlike OTU 11146, OTU 7940 exhibited a significant association to one contextual parameter (TERR_FA). The Betaprotebacteria OTU 11154, the second most abundant OTU, also had a specialized niche in our samples. It was most abundant in June and in the top part of the sediment column section and it showed a significant positive correlation with Phyto_PUFA. It was $100 \%$ identical to Rhodoferax ferrireducens, strain T118, an iron reducing nonfermenting facultative aerobe that can also use iron nitrate and $\mathrm{Mn}(\mathrm{IV})$ oxide as electron acceptor (Finneran et al., 2003) and several smaller organic acids (for example, acetate, lactate and butyrate) as electron donors.

It has been hypothesized that a greater proportion of $\mathrm{OM}$ is remineralized through anaerobic pathways and that a greater part of the $\mathrm{O}_{2}$ flux is used for reoxidation of reduced solutes in this kind of dynamic deltaic sedimentary system (Lansard et al., 2009; Pastor et al., 2011). Thus, one would expect to find microorganisms that are more specialized in the utilization of smaller reduced acids, like Rhodoferax ferrireducens described above, supporting the idea of the reoxidation of intermediate products from incomplete anaerobic degradation of OM (fermentation or acetogenesis). We did find some indications for the presence of other microorganisms with similar or complimentary metabolisms. One example is the presence of bacteria belonging to the genus Spirochaetes (all the Spirochaetaceae sequences belonged to this genus) that contains anaerobic or facultative aerobic bacteria (Paster et al., 1991). The relative abundance of Spirochaetes showed a correlation with $\delta^{13} \mathrm{C}$ values and, indeed, they are common degraders of plant material in aquatic environments and can ferment a number of saccharidic substrates (Leschine et al., 2006). The $\delta^{13} \mathrm{C}$ values also correlated with some betaproteobacterial OTUs. For example, the betaproteobacterial OTU 3013 was 99\% identical to several species within the genus Hydrogenophaga, and family Comamonadaceae that are characterized by the ability to oxidize hydrogen and can also grow aerobically or reduce nitrate using a number of organic compounds, mainly organic acids (Willems et al., 1989). Indeed, we found substantial amounts of Betaproteobacteria sequences within this and the Rhodocyclaceae family, mostly within the genus Dechloromonas. Bacteria within this genus are aerobic, nonfermentative and can utilize acetate and other organic acids as carbon sources and nitrate as alternative electron acceptors (Achenbach et al., 2001). Lastly, the relative abundance of bacteria within the order Desulfuromonadales, including the abundant OTU 11225 that are thought to be important in iron reduction coupled to acetate oxidation (Vandieken and Thamdrup, 2013), supports this hypothesis of cycling of smaller, more intermediate carbon compounds.

The contextual parameters that we measured in this study were focused on OM quality and source, and could explain at the most $17 \%$ of the total variance of the microbial community. This low value suggests that other contextual parameters not measured here are important (for example, nutrients, available electron acceptors) and/or that biotic factors are also a major factor. Biotic interactions like competition, mutualism or commensalism can be key ecological structuring factors and can be investigated through co-occurrence of taxa/OTUs and phylogenetic clustering/dispersion patterns. The pattern that we detected by calculating the C-score (Stone and Roberts, 1990) indicated nonrandom co-occurrence and more specifically segregation. Nonrandom co-occurrence patterns indicate that deterministic processes were indeed shaping the microbial community, and segregation suggests that 
OTUs in the prodelta occurred together less often than expected by chance. A pattern of segregation may appear surprising, as one might expect a certain level of co-occurrence, especially as syntrophic interactions between different microbial taxa are generally important when complex OM is degraded under anoxic conditions (Wolin and Miller, 1987; McInerney et al., 2009). However, our results are in line with an earlier report that found segregation to be the predominant structuring factor of microbial communities in a variety of environments (HornerDevine et al., 2007), but in contrast to Barberan et al. (2012) who found that microorganisms from soil cooccurred more often than expected by chance.

The significant segregation patterns could mean that competitive interactions between OTUs drives community assembly but it could also be a result of non-overlapping niches (habitat checkerboard) or historical effect (see, for example, Diamond, 1975; Gotelli et al., 1997; Horner-Devine et al., 2007). Phylogenetic clustering patterns can give deeper insight into the underlying ecological processes (Webb et al., 2002; Horner-Devine and Bohannan, 2006) especially when performed on each sample separately. Although very few of our samples were significantly phylogenetically clustered or dispersed, we did observe more phylogenetic clustering in deep samples in August, suggesting that the community was shaped by habitat filtering, a process that is arguably the most predominant process in shaping microbial communities (Horner-Devine and Bohannan, 2006; Pontarp et al., 2012; Wang et al., 2012), although it can depend on OTU definitions (Koeppel and $\mathrm{Wu}, 2014$ ). Thus, with less perturbation, the community probably became more specialized toward specific environmental conditions. This abiotic filtering corresponded to higher proportion of TERR_FA and SAFA, emphasizing the structuring effect of these parameters on the microbial community. However, these same processes did not dominate at all times. In surface samples in February, we observed significant phylogenetic overdispersion that is consistent with biotic forces structuring community assembly, reflecting the action of negative interactions such as competition (Webb et al., 2002). The relative importance of deterministic and stochastic processes can change with time (Stegen et al., 2012). Indeed, our phylogenetic analysis highlighted that the main deterministic processes that ruled community assembly changed with time and depth, switching from biotic to abiotic control of the community composition.

\section{Conclusion}

In the Rhône prodelta system, the microbial community present at a certain time was highly influenced by the variable river flow. In this dynamic environment, the relative importance of physical, chemical or biotic factors changed with season and depth, but the structuring drivers of the microbial community remained closely linked to the sources and quality of the OM input. Our work emphasizes the need to increase the repertoire of contextual parameters, including parameters like SAFA and Phyto_PUFA, in order to obtain a more comprehensive picture of the relationship between microbes and OM.

\section{Conflict of Interest}

The authors declare no conflict of interest.

\section{Acknowledgements}

We thank Christophe Rabouille, chief scientist of the MESURHOBENT cruises and coordinator of the MERMEX-RIVERS program. We thank the captain and crew of the RV Tethys II, as well as numerous colleagues, for their hard work at sea and in the laboratory. In particular, we thank Béatrice Rivière and Lionel Feuillassier from LECOB for their help with pigment and grain size analyses. Pigment concentration calculations were made using the calibration developed by François Lantoine (LECOB). We are grateful to Matthew Oliver (University of Delaware, USA) for help with R scripts for the MIC analysis, to Jeff Ghiglione and Dimitri Kalenitchenko for help with statistical analysis and Marcelino T Suzuki for his help with installing and updating QIIME and Mothur on local computer servers. Access to molecular biology instrumentation and facilities were provided through the BIO2MAR platform (http://bio2mar.obs-banyuls.fr). This research was funded by the French program MISTRALS/ MERMEX, the CNRS, UPMC and in part by the ECOPOP project led by FC in the framework of 'EC2CO/CNRSINSU'. SB was supported by a grant from the French Ministry of Research. PEG and SKF were supported by the Agence Nationale de la Recherche (ANR) project MICADO (ANR-11JSV7-003-01). Rhône River discharge data were provided by the server Inforhône of the "Compagnie Nationale du Rhône" (CNR). The material is original work and has not been submitted for publication elsewhere.

\section{References}

Achenbach LA, Michaelidou U, Bruce RA, Fryman J, Coates JD. (2001). Dechloromonas agitata gen. nov., sp. nov. and Dechlorosoma suillum gen. nov., sp. nov., two novel environmentally dominant (per)chloratereducing bacteria and their phylogenetic position. Int $J$ Syst Evol Microbiol 51: 527-533.

Aller JY, Aller RC. (2004). Physical disturbance creates bacterial dominance of benthic biological communities in tropical deltaic environments of the Gulf of Papua. Cont Shelf Res 24: 2395-2416.

Aller JY, Aller RC, Kemp PF, Chistoserdov AY, Madrid VM. (2010). Fluidized muds: a novel setting for the generation of biosphere diversity through geologic time. Geobiology 8: 169-178.

Aller RC. (1998). Mobile deltaic and continental shelf muds as suboxic, fluidized bed reactors. Mar Chem 61: 143-155. 
Aloisi JC, Millot C, Monaco A, Pauc H. (1979). Suspensate dynamics and mechanisms of sediment genesis on the Gulf of Lion continental-shelf. $C R$ Acad Sci Hebd Seances Acad Sci D289: 879-882.

Antonelli C, Eyrolle F, Rolland B, Provansal M, Sabatier F. (2008). Suspended sediment and 137Cs fluxes during the exceptional December 2003 flood in the Rhône River, southeast France. Geomorphology 95: 350-360.

Baldock JA, Masiello CA, Gélinas Y, Hedges JI. (2004). Cycling and composition of organic matter in terrestrial and marine ecosystems. Mar Chem 92: 39-64.

Barberan A, Bates ST, Casamayor EO, Fierer N. (2012). Using network analysis to explore co-occurrence patterns in soil microbial communities. ISME $J$ 6: 343-351.

Bianchi TS. (2011). The role of terrestrially derived organic carbon in the coastal ocean: A changing paradigm and the priming effect. Proc Natl Acad Sci USA 108: 19473-19481.

Bianchi TS, Canuel EA. (2011). Lipids: fatty acids. In: Chemical Biomarkers in Aquatic Ecosystems. Princeton University Press.

Bienhold C, Boetius A, Ramette A. (2012). The energydiversity relationship of complex bacterial communities in Arctic deep-sea sediments. ISME J 6: 724-732.

Blanquer A, Uriz MJ, Galand PE. (2013). Removing environmental sources of variation to gain insight on symbionts vs. transient microbes in high and low microbial abundance sponges. Environ Microbiol 15: 3008-3019.

Bourgeois S, Pruski AM, Sun M-Y, Buscail R, Lantoine F, Kerhervé $\mathrm{P}$ et al. (2011). Distribution and lability of land-derived organic matter in the surface sediments of the Rhône prodelta and the adjacent shelf (Mediterranean Sea, France): a multi proxy study. Biogeosciences 8: 3107-3125.

Caporaso JG, Kuczynski J, Stombaugh J, Bittinger K, Bushman FD, Costello EK et al. (2010). QIIME allows analysis of high-throughput community sequencing data. Nat Methods 7: 335-336.

Cathalot C, Rabouille C, Pastor L, Deflandre B, Viollier E, Buscail R et al. (2010). Temporal variability of carbon recycling in coastal sediments influenced by rivers: assessing the impact of flood inputs in the Rhône River prodelta. Biogeosciences 7: 1187-1205.

Cathalot C, Rabouille C, Tisnérat-Laborde N, Toussaint F, Kerhervé P, Buscail R et al. (2013). The fate of river organic carbon in coastal areas: a study in the Rhône River delta using multiple isotopic ( $\delta 13 \mathrm{C}, \Delta 14 \mathrm{C})$ and organic tracers. Geochim Cosmochim Acta 118: 33-55.

Cauwet G, Gadel F, de Souza Sierra MM, Donard O, Ewald M. (1990). Contribution of the Rhône River to organic carbon inputs to the northwestern Mediterranean Sea. Cont Shelf Res 10: 1025-1037.

Charles F, Guarini-Coston J, Lantoine F, Guarini JM, Yücel M. (2014). Ecogeochemical fate of coarse organic particles in sediments of the Rhône River prodelta. Estuar Coast Shelf Sci 141: 97-103.

Darnaude A, Salen-Picard C, Polunin NC, Harmelin-Vivien M. (2004). Trophodynamic linkage between river runoff and coastal fishery yield elucidated by stable isotope data in the Gulf of Lions (NW Mediterranean). Oecologia 138: 325-332.

Dauwe B, Middelburg JJ. (1998). Amino acids and hexosamines as indicators of organic matter degradation state in North Sea sediments. Limnol Oceanogr 43: $782-798$.
Diamond JM. (1975). Assembly of species communities. In: Cody ML, Diamond JM (eds) Ecology and Evolution of Communities. Belknap Press: Cambridge, MA, pp $342-444$.

Edgar RC. (2010). Search and clustering orders of magnitude faster than BLAST. Bioinformatics 26: 2460-2461.

Efron B. (2004). Large-scale simultaneous hypothesis testing: the choice of a null hypothesis. J Am Stat Assoc 99: 96-104.

Fagervold SK, Bessette S, Romano C, Martin D, Plyuscheva M, LeBris N et al. (2013). Microbial communities associated with the degradation of oak wood in the Blanes submarine canyon and its adjacent open slope (NW Mediterranean). Prog Oceanogr 118: 137-143.

Finneran KT, Johnsen CV, Lovley DR. (2003). Rhodoferax ferrireducens sp. nov., a psychrotolerant, facultatively anaerobic bacterium that oxidizes acetate with the reduction of $\mathrm{Fe}(\mathrm{III})$. Int $J$ Syst Evol Microbiol 53: 669-673.

Franco MA, De Mesel I, Diallo MD, Van der Gucht K, Van Gansbeke D, Van Rijswijk P et al. (2007). Effect of phytoplankton bloom deposition on benthic bacterial communities in two contrasting sediments in the southern North Sea. Aquat Microb Ecol 48: 241-254.

Froelich P, Klinkhammer G, Bender M, Luedtke N, Heath G, Cullen D et al. (1979). Early oxidation of organic matter in pelagic sediments of the eastern Atlantic: suboxic diagenesis. Geochim Cosmochim Acta 43: 1075-1090.

Gobet A, Boeer SI, Huse SM, van Beusekom JEE, Quince C, Sogin ML et al. (2012). Diversity and dynamics of rare and of resident bacterial populations in coastal sands. ISME J 6: 542-553.

Gotelli NJ et al. (1997). Co-occurrence of Australian land birds: Diamond's assembly rules revisited. Oikos 80: 311-324.

Harmelin-Vivien M, Dierking J, Banaru D, Fontaine MF, Arlhac D. (2010). Seasonal variation in stable C and N isotope ratios of the Rhône River inputs to the Mediterranean Sea (2004-2005). Biogeochemistry 100: 139-150.

Harmelin-Vivien M, Loizeau V, Mellon C, Beker B, Arlhac D, Bodiguel X et al. (2008). Comparison of C and N stable isotope ratios between surface particulate organic matter and microphytoplankton in the Gulf of Lions (NW Mediterranean). Cont Shelf Res 28: 1911-1919.

Hedges JI, Kiel RG, Benner R. (1997). What happens to terrestrial organic matter in the ocean? Org Geochem 27: 195-212.

Higueras M, Kerhervé P, Sanchez-Vidal A, Calafat A, Ludwig W, Verdoit-Jarraya M et al. (2014). Biogeochemical characterization of the riverine organic matter transferred to the NW Mediterranean Sea. Biogeosciences 11: 157-172.

Horner-Devine MC, Bohannan BJM. (2006). Phylogenetic clustering and overdispersion in bacterial communities. Ecology 87: S100-S108.

Horner-Devine MC, Silver JM, Leibold MA, Bohannan BJM, Colwell RK, Fuhrman JA et al. (2007). A comparison of taxon co-occurrence patterns for macro- and microorganisms. Ecology 88: 1345-1353.

$\mathrm{Hu}$ JF, Zhang HB, Peng PA. (2006). Fatty acid composition of surface sediments in the subtropical Pearl River estuary and adjacent shelf, Southern China. Estuar Coast Shelf Sci 66: 346-356. 
Jorgensen SL, Hannisdal B, Lanzen A, Baumberger T, Flesland K, Fonseca R et al. (2012). Correlating microbial community profiles with geochemical data in highly stratified sediments from the Arctic Mid-Ocean Ridge. Proc Natl Acad Sci USA 109: E2846-E2855.

Kembel SW, Cowan PD, Helmus MR, Cornwell WK, Morlon H, Ackerly DD et al. (2010). Picante: R tools for integrating phylogenies and ecology. Bioinformatics 26: 1463-1464.

Kerhervé P, Minagawa M, Heussner S, Monaco A. (2001). Stable isotopes (C-13/C-12 and N-15/N-14) in settling organic matter of the northwestern Mediterranean Sea: biogeochemical implications. Oceanologica Acta 24: S77-S85.

Kim J-H, Zarzycka B, Buscail R, Peterse F, Bonnin J, Ludwig W et al. (2010). Contribution of riverborne soil organic carbon to the Gulf of Lions (NW Mediterranean). Limnol Oceanogr 55: 507-518.

Koeppel AF, Wu M. (2014). Species matter: the role of competition in the assembly of congeneric bacteria. ISME J 8: 531-540.

Kuczynski J, Liu Z, Lozupone C, McDonald D, Fierer N, Knight R. (2010). Microbial community resemblance methods differ in their ability to detect biologically relevant patterns. Nat Meth 7: 813-819.

Lansard B, Rabouille C, Denis L, Grenz C. (2009). Benthic remineralization at the land-ocean interface: A case study of the Rhône River (NW Mediterranean Sea). Estuar Coast Shelf Sci 81: 544-554.

Lansard B, Rabouille C, Denis L, Grenz C. (2008). In situ oxygen uptake rates by coastal sediments under the influence of the Rhône River (NW Mediterranean Sea). Cont Shelf Res 28: 1501-1510.

Leschine S, Paster B, Canale-Parola E. (2006). Free-living saccharolytic Spirochetes: the genus Spirochaeta. In Dworkin M, Falkow S, Rosenberg E, Schleifer K-H, Stackebrandt E (eds) The Prokaryotes. Springer: New York, pp 195-210.

Lindroth P, Mopper K. (1979). High performance liquid chromatographic determination of subpicomole amounts of amino acids by precolumn fluorescence derivatization with ortho-phthaldialdehyde. Anal Chem 51: 1667-1674.

Lozupone C, Knight R. (2005). UniFrac: a new phylogenetic method for comparing microbial communities. Appl Environ Microbiol 71: 8228-8235.

Lozupone CA, Hamady M, Kelley ST, Knight R. (2007). Quantitative and qualitative $\beta$ diversity measures lead to different insights into factors that structure microbial communities. Appl Environ Microbiol 73: 1576-1585.

Madrid VM, Aller JY, Aller RC, Chistoserdov AY. (2001). High prokaryote diversity and analysis of community structure in mobile mud deposits off French Guiana: identification of two new bacterial candidate divisions. FEMS Microbiol Ecol 37: 197-209.

Madrid VM, Aller RC, Aller JY, Chistoserdov AY. (2006). Evidence of the activity of dissimilatory sulfatereducing prokaryotes in nonsulfidogenic tropical mobile muds. FEMS Microbiol Ecol 57: 169-181.

Marion C, Dufois F, Arnaud M, Vella C. (2010). In situ record of sedimentary processes near the Rhône River mouth during winter events (Gulf of Lions, Mediterranean Sea). Cont Shelf Res 30: 1095-1107.

McInerney MJ, Sieber JR, Gunsalus RP. (2009). Syntrophy in anaerobic global carbon cycles. Curr Opin Biotech 20: $623-632$.
Miralles J, Arnaud M, Radakovitch O, Marion C, Cagnat X. (2006). Radionuclide deposition in the Rhône River Prodelta (NW Mediterranean sea) in response to the December 2003 extreme flood. Mar Geol 234: 179-189.

Neveux J, Lantoine F. (1993). Spectrofluorometric assay of chlorophylls and pheopigments using the least squares approximation technique. Deep Sea Res Part 1 Oceanogr Res Pap 40: 1747-1765.

Oksanen J, Blanchet FG, Kindt R, Legendre P, Minchin PR, O’Hara B et al. (2012). vegan: Community ecology packagehttp://cran.r-project.org/web/packages/vegan/ index.html.

Paster BJ, Dewhirst FE, Weisburg WG, Tordoff LA, Fraser GJ, Hespell RB et al. (1991). Phylogenetic analysis of the spirochetes. J Bacteriol 173: 6101-6109.

Pastor L, Cathalot C, Deflandre B, Viollier E, Soetaert K, Meysman FJR et al. (2011). Modeling biogeochemical processes in sediments from the Rhône River prodelta area (NW Mediterranean Sea). Biogeosciences 8: 1351-1366.

Polymenakou PN, Bertilsson S, Tselepides A, Stephanou EG. (2005). Links between geographic location, environmental factors, and microbial community composition in sediments of the Eastern Mediterranean Sea. Microb Ecol 49: 367-378.

Pont D. (1997). Les débits solides du Rhône à proximité de son embouchure: données récentes (1994-1995). Rev Geogr Lyon 72: 23-33.

Pontarp M, Canbäck B, Tunlid A, Lundberg P. (2012). Phylogenetic analysis suggests that habitat filtering is structuring marine bacterial communities across the globe. Microb Ecol 64: 8-17.

Price MN, Dehal PS, Arkin AP. (2009). FastTree: computing large minimum evolution trees with profiles instead of a distance matrix. Mol Biol Evol 26: 1641-1650.

Quast C, Pruesse E, Yilmaz P, Gerken J, Schweer T, Yarza P et al. (2013). The SILVA ribosomal RNA gene database project: improved data processing and web-based tools. Nucleic Acids Res 41: D590-D596.

Quince C, Lanzen A, Davenport RJ, Turnbaugh PJ. (2011). Removing noise from pyrosequenced amplicons. BMC Bioinformatics 12.

Radakovitch O, Charmasson S, Arnaud M, Bouisset P. (1999). Pb-210 and caesium accumulation in the Rhône delta sediments. Estuar Coast Shelf Sci 48: 77-92.

Reshef DN, Reshef YA, Finucane HK, Grossman SR, McVean G, Turnbaugh PJ et al. (2011). Detecting novel associations in large data sets. Science 334: 1518-1524.

Schloss PD, Westcott SL, Ryabin T, Hall JR, Hartmann M, Hollister EB et al. (2009). Introducing mothur: opensource, platform-independent, community-supported software for describing and comparing microbial communities. Appl Environ Microbiol 75: 7537-7541.

Sempéré R, Charrière $B$, Van Wambeke $F$, Cauwet G. (2000). Carbon inputs of the Rhône River to the Mediterranean Sea: biogeochemical implications. Global Biogeochem Cycles 14: 669-681.

Shannon P, Markiel A, Ozier O, Baliga NS, Wang JT, Ramage $\mathrm{D}$ et al. (2003). Cytoscape: a software environment for integrated models of biomolecular interaction networks. Genome Res 13: 2498-2503.

Stegen JC, Lin X, Konopka AE, Fredrickson JK. (2012). Stochastic and deterministic assembly processes in subsurface microbial communities. ISME J 6: 1653-1664. 
Stone L, Roberts A. (1990). The checkerboard score and species distributions. Oecologia 85: 74-79.

Teske A, Alm E, Regan JM, Toze S, Rittmann BE, Stahl DA. (1994). Evolutionary relationships among ammoniaoxidizing and nitrite-oxidizing bacteria. $J$ Bacteriol 176: $6623-6630$.

Vandieken V, Thamdrup B. (2013). Identification of acetate-oxidizing bacteria in a coastal marine surface sediment by RNA-stable isotope probing in anoxic slurries and intact cores. FEMS Microbiol Ecol 84: 373-386.

Vergin KL, Urbach E, Stein JL, DeLong EF, Lanoil BD, Giovannoni SJ. (1998). Screening of a fosmid library of marine environmental genomic DNA fragments reveals four clones related to members of the order Planctomycetales. Appl Environ Microbiol 64: $3075-3078$.

Volkman JK. (2006). Lipid markers for marine organic matter. In Volkman JK (ed) Marine Organic Matter: Biomarkers, Isotopes and DNA, The Handbook of Environmental Chemistry. Springer: Berlin, Heidelberg, pp 27-70.

Vo $\beta$ M, Struck U. (1997). Stable nitrogen and carbon isotopes as indicator of eutrophication of the Oder river (Baltic sea). Mar Chem 59: 35-49.
Wang J, Soininen J, He J, Shen J. (2012). Phylogenetic clustering increases with elevation for microbes. Environ Micro Rep 4: 217-226.

Wang Q, Garrity GM, Tiedje JM, Cole JR. (2007). Naive Bayesian classifier for rapid assignment of rRNA sequences into the new bacterial taxonomy. Appl Environ Microbiol 73: 5261-5267.

Webb CO, Ackerly DD, Kembel SW. (2008). Phylocom: software for the analysis of phylogenetic community structure and trait evolution. Bioinformatics 24: 2098-2100.

Webb CO, Ackerly DD, McPeek MA, Donoghue MJ. (2002). Phylogenies and community ecology. Annu Rev Ecol Syst 33: 475-505.

Willems A, Busse J, Goor M, Pot B, Falsen E, Jantzen E et al. (1989). Hydrogenophaga, a new genus of hydrogenoxidizing bacteria that includes Hydrogenophaga flava comb. nov. (Formerly Pseudomonas flava), Hydrogenophaga palleronii (Formerly Pseudomonas palleronii), Hydrogenophaga pseudoflava (Formerly Pseudomonas pseudoflava and 'Pseudomonas carboxydoflava'), and Hydrogenophaga taeniospiralis (Formerly Pseudomonas taeniospiralis). Int J Syst Bacteriol 39: 319-333.

Wolin MJ, Miller TL. (1987). Bioconversion of organic carbon to CH4 and CO2. Geomicrobiol J 5: 239-259.

Supplementary Information accompanies this paper on The ISME Journal website (http://www.nature.com/ismej) 